\title{
Identification and Evaluation of Factors Affecting the Eutrophication of Wuxing Lake
}

\author{
Feng $\mathrm{Gao}^{1}$, Ying Qiao ${ }^{2}$, Weihong Wang ${ }^{1}$, Suiju Lv ${ }^{1 *}$ \\ ${ }^{1}$ School of Civil Engineering, North Minzu University, Yinchuan 750021, China \\ ${ }^{2}$ Mathematics and Information Science, North Minzu University, Yinchuan 750021, China
}

Corresponding Author Email: 2005060@nmu.edu.cn

https://doi.org/10.18280/ijdne.150419

Received: 5 March 2020

Accepted: 12 June 2020

\author{
Keywords: \\ eutrophication, Wuxing Lake, evaluation, \\ influencing factors
}

\begin{abstract}
Lake eutrophication is a major problem with water environment around the world. It is of great ecological significance to identify and control the inducing factors of lake eutrophication. This paper explores the causes of the eutrophication of Wuxing Lake from external conditions, sources of nutrients, and the relationship between nutrients and eutrophication. The influencing factors of lake eutrophication were subject to correlation analysis, revealing how much each factor affects the degree of eutrophication. The results show that temperature has the greatest impact on the eutrophication of Wuxing Lake, followed by total phosphorus (TP); current speed is the weakest impact factor. Hence, external conditions have a significant effect on the eutrophication of Wuxing Lake. Nitrogen and phosphorus, as nutrients for algae and other phytoplankton, also contribute greatly to the eutrophication of Wuxing Lake. The research results contribute greatly to the healthy development of Wuxing Lake and the sustainable economic growth of the surrounding regions.
\end{abstract}

\section{INTRODUCTION}

Eutrophication is a prominent problem of shallow lakes, which attracts much attention from the academia. The eutrophication of shallow lakes will lead to a series of ecological and environmental problems, endanger the safety of drinking water, and even threat economic sustainability and social stability. For example, the Taihu Lake, the source of tap water in Wuxi City, was plagued by the blue-green alga bloom from May to June 2007. The ensuing shortage of domestic water and drinking water seriously disrupted the daily life of residents, posing a severe danger to the sustainable development of regional economy and society [1-8].

Currently, China has launched several scientific research projects to deal with the eutrophication of lakes and reservoirs. These projects have achieved fruitful results on the formation mechanism of lake and reservoir eutrophication. However, different lakes and reservoirs vary in pollution features and eutrophication causes. Therefore, specific research must be conducted on each lake or reservoir.

Wuxing Lake is a shallow semi-closed lake, which suffered multiple algal blooms in recent years. The relentless growth of algae seriously lowers the dissolved oxygen (DO) in the lake, causing the death of lots of fish. This has greatly damaged the ecological environment of Wuxing Lake. It is imperative to curb the eutrophication, and restore the healthy ecosystem of Wuxing Lake. To effectively solve the eutrophication problem, this paper attempts to identify the causes and influencing factors of the eutrophication in Wuxing Lake.

\section{METHODOLOGY}

Correlation analysis is a data mining approach that discovers the connections between different things. There are mainly four steps of correlation analysis:

Step 1. Determining the affected factor and influencing factors

The affected factor is the research subject. Correlation analysis aims to quantify the correlations between the affected factor and the influencing factors.

Step 2. Raw data processing

In general, the various influencing factors have marked difference in dimensionality and value. To eliminate the effects of such differences, the raw data should be normalized by:

$$
x^{*}=\left(x_{i}-x_{\min }\right) /\left(x_{\max }-x_{\min }\right)
$$

where, $x^{*}$ is the normalized value; $x_{\max }$ is the maximum value of the monitored data; $x_{\min }$ is the minimum value of the monitored data.

Step 3. Determining the correlation coefficient

The correlation coefficient $\delta_{0 \mathrm{i}}(k)$ can be calculated by:

$$
\delta_{\mathrm{Oi}}(k)=\left(\Delta_{\min }+\rho * \Delta_{\max }\right) /\left(\Delta_{\mathrm{o} i}(k)+\rho * \Delta_{\max }\right)
$$

where, $\Delta_{0 \mathrm{i}}(k)=\left|\Delta_{0}(k)-\Delta_{\mathrm{i}}(k)\right|$ is the absolute difference between influencing factors; $\Delta_{\min }$ and $\Delta_{\max }$ are the maximum and minimum absolute differences between influencing factors, respectively; $\rho \in(0,1)$ is the coefficient of resolution, which is generally 0.5 .

Step 4. Determining the degree of correlation The degree of correlation $r_{0 \mathrm{i}}$ can be calculated by: 


$$
r_{0 i}=\frac{1}{N} \sum_{k=1}^{N} \delta_{0 i}(k)
$$

\section{RESULTS ANALYSIS}

\subsection{Causes of eutrophication in Wuxing Lake}

The eutrophication brings great harm to water bodies like lakes. Lake eutrophication has attracted much attention at home and abroad. Studies have attributed lake eutrophication to the combined action of external conditions and nutrients. Thus, it is important to study whether the external conditions of Wuxing Lake are suitable for the formation of eutrophication, what are the sources of pollutants, and what is the relationship between nutrients and eutrophication in the lake.

\subsubsection{External conditions of eutrophication}

Lake eutrophication has a lot to do with external conditions, namely hydrodynamic condition, temperature, light, and potential of hydrogen $(\mathrm{pH})$. If the external conditions are not favorable, the algae in the lake will not grow excessively. In this case, the algae growth will not cause great harm to the lake, even if the lake is rich in nutrients.

(1) Wuxing Lake, as a shallow lake located in the temperate zone, carries obvious seasonal changes in temperature. There is little difference but a close correlation between water temperature and air temperature. Studies have shown that, despite slight differences, the most suitable temperatures for different algae to grow are around $20^{\circ} \mathrm{C}$. From April to October, the air temperature of Wuxing Lake falls between $10^{\circ} \mathrm{C}$ and $30^{\circ} \mathrm{C}$, which is suitable for algae growth. In this period, the lake has a high content of chlorophyll a (Chl-a), a sign of frequent occurrence of algal blooms. By contrast, the air temperature is below $10^{\circ} \mathrm{C}$ from November to next March, which is unfavorable for algae growth. In this period, the Chla content remains low, that is, the lake does not suffer from algal bloom.
(2) Light has a certain impact on lake eutrophication, mainly on the photosynthesis of algae and other phytoplankton. The eutrophication of the lake is affected how sensitive each alga is to light. Wuxing Lake meets the light and heat conditions for eutrophication: the annual mean sunshine duration is $2,375 \mathrm{~h}$, and the annual mean solar radiation is $123.7 \mathrm{cal} / \mathrm{cm}^{2}$.

(3) Hydrodynamic condition has a great impact on lake eutrophication. Currently, it is an important way to mitigate lake eutrophication by changing the hydrodynamic condition. The existing studies have shown that, under different boundary conditions, the current speed should be slower than $0.05 \mathrm{~m} / \mathrm{s}$ for eutrophication to take place. When the external hydrological and meteorological conditions are suitable, the critical current speed for algae growth in Wuxing Lake is $0.05 \mathrm{~m} / \mathrm{s}$. The current speed was sampled at five points in Wuxing Lake. The sampling results (Figure 1) show that the current speed was slower than $0.03 \mathrm{~m} / \mathrm{s}$ most of the time, satisfying the hydrodynamic condition required for eutrophication.

In practice, it is unrealistic to mitigate the eutrophication of water bodies by changing the light and temperature. For rivers, it is not a difficult task to change hydrodynamic condition. However, a huge amount of external water is needed to alter the hydrodynamic condition of lakes. The exact amount of water required needs to be analyzed based on the situation of each lake.

The main surface water source of Wuxing Lake is Sushui River, whose current speed is about $0.69 \mathrm{~m}^{3} / \mathrm{s}$. Suppose the water quality of the river is acceptable. The amount of water discharged by the river to Wuxing Lake is not enough to change the state of wind-driven current in the lake, that is, the current speed of the lake will stay below $0.05 \mathrm{~m} / \mathrm{s}$ despite the water inflow. Hence, the hydrodynamic condition of Wuxing Lake will not be altered by the surface water supply, and favor the growth of algae.

To sum up, the external conditions (e.g. temperature, light, and hydrodynamic condition) of Wuxing Lake are suitable for eutrophication.

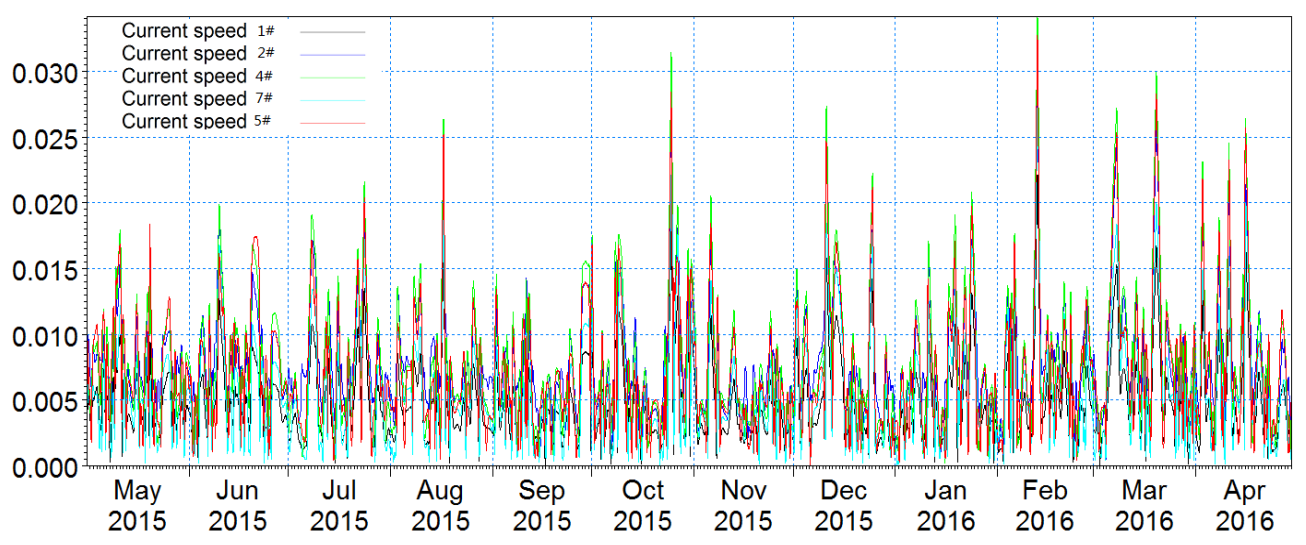

Figure 1. The current speed curves at 5 sampling points in Wuxing Lake

\subsubsection{Pollution sources}

The external conditions for the eutrophication of Wuxing Lake have been thoroughly analyzed in the preceding paragraphs. To disclose the eutrophication mechanism, it is necessary to identify the sources of nutrients in the lake, and clarify their correlations with eutrophication.

(1) Industrial pollution
According to preliminary statistics, the industrial enterprises in Sushui River Basin discharge a total of 8.677556 million tons of industrial wastewater, 1,775.8931 tons of organic pollutants, and 184.4615 tons of ammonia nitrogen $\left(\mathrm{NH}_{3}-\mathrm{N}\right)$. The emissions of wastewater and pollutants are expected to further grow. Overall, the water of Sushui River is seriously polluted by various pollutants, showing large 
changes in pollution load. Due to the extremely poor water quality, the river is a severely polluted water body, which belongs to Class V in Environmental Quality Standards for Surface Water (GB3838-2002).

In fact, the river has become a drainage ditch for the industrial wastewater discharged by upstream enterprises, domestic wastewater discharged by upstream residents, and the substandard mixed wastewater discharged by sewage treatment plants. The huge amount of wastewater and pollutants seriously threat the water environment of Wuxing Lake, and serve as the main sources of pollutants that destroy the quality of the water environment.

Several attempts have been made to rehabilitate the Sushui River, but to no avail. The water environment is still seriously polluted, and the pollution is poised to worsen. As the main city in Sushui River Basin, Yuncheng City and its subordinate counties have highly irrational and imbalanced industrial layout and product structure. Many enterprises below the designated size are scattered across the basin, using backward production technology. What is worse, most imported enterprises are featured by high energy consumption, high pollution, low efficiency, and backward technology. As a result, lots of industrial wastewater are discharged into the river, resulting in heavy industrial pollution, and putting a huge stress on regional water environment. The serious water pollution also suppresses economic benefits.

According to incomplete statistics, there are at least 23 polluting enterprises along Sushui River, including 7 chemical enterprises, 5 textile printing and dyeing enterprises, 5 food processing enterprises, 2 metal smelting enterprises, 1 papermaking enterprise, 1 wood processing enterprise, 1 slaughtering enterprise, and 1 material product enterprise. In total, these enterprises discharge a staggering amount of $6,557,553 \mathrm{~m}^{3} / \mathrm{d}$ of wastewater. The wastewater treatment technology of these enterprises is relatively backward, and not strictly supervised by local environmental authority. Most enterprises directly discharge substandard wastewater into Sushui River, further aggravating river pollution. The wastewater eventually enters Wuxing Lake and directly threatens the water environment.

To solve the problem, the embankment of Sushui River has been elevated to prevent the river water from flowing into the lake. Instead, some water has been diverted from the Yellow River to replenish Wuxing Lake. Considering the scarce water resources in northern China, the diversion is not a long-term solution. The water of Sushui River should be fully treated before being discharged into Wuxing Lake. In this way, the water environment of Wuxing Lake can be safeguarded, while reducing the amount of water diverted from the Yellow River.

(2) Agricultural non-point source pollution

Through field investigations, the authors discovered that most shores of Wuxing Lake have been reclaimed, and developed into an important agricultural area. During the dry season, local farmers have reclaimed the exposed lakebed, turning almost all the shores into low-yield farmlands. Some farmlands extend directly to the lake. There is even a Wuxing Lake Farm on the east bank of the lake. The farmlands are planted with sorghum, corn, wheat, cotton, and other crops. At present, there is virtually no natural vegetation on the shores. In most places, the shores are surrounded by farmlands and fruit trees. Hence, Wuxing Lake lacks basic ecological protection functions.

The location of Wuxing Lake lies on the southern edge of the Loess Plateau, where the soil is relatively poor and seriously eroded. The local agricultural production relies too much on chemical fertilizers and pesticides, causing serious pollution to the lake. Each year, Yuncheng City applies 360,000 tons of chemical fertilizers and 12.67 million tons of pesticides. Yongji City, a county-level city under Yuncheng, produced 86,100 tons of nitrogen fertilizers, and consumed 64,000 tons of chemical fertilizers. It is equivalent to applying $50.56 \mathrm{~kg}$ nitrogen fertilizers per mu of land. The amount of fertilizers used in agricultural production of this region far exceeds the average fertilizer rate in China. The excess fertilizers and pesticides cannot be fully utilized by crops.

Relevant data have shown that $60 \%$ of chemical fertilizers applied in China are lost. Large amounts of chemical fertilizers (the excess nitrogen and phosphate fertilizers) and various pesticides are carried to low-lying areas by surface runoff. Since the lake shores lack ecological protection functions, these pollutants eventually end up in Wuxing Lake, resulting in serious agricultural non-point source pollution. Therefore, agricultural non-point source pollution is another important pollution source of the water environment of the lake. To eradicate the pollution, the key lies in controlling the agricultural non-point source pollution.

(3) Fly ash

Since the 1970s, Yongji Power Plant has dumped its waste fly ash into Wuxing Lake or piled it on the lakeshore. Currently, there is a $1,123 \mathrm{mu}$ fly ash yard (length: $74.9 \mathrm{~m}$; width: $104 \mathrm{~m}$ ) on the northeast shore of the lake. The piles of fly ash are as tall as $8 \mathrm{~m}$. The fly ash is carried from the northeast shore by wind and surface runoff right into the lake.

Many scholars have pointed out that the waste fly ash from the power plant has an adverse effect on the water quality of the lake, threatening the water environment. Of course, there is no detailed analysis on the composition of the fly ash, or how the fly ash affects the water quality of the lake. But the existing research has confirmed that the fly ash has not only exacerbated the pollution of the water environment, but also brought new pollutants.

(4) Fish farming

The northern part of Wuxing Lake has been contracted to local fishermen for fish farming. The entire surface of the northern part has become a "fish pond". The southern part is evenly more heavily utilized by many fish farmers. The fish farming covers a large area, although the fish farming method is extensive, without applying too many fish feeds. Field surveys have confirmed the high density of fish in the lake. Fish are often seen jumping out of the water. The excrement of so many fish, coupled with the fish feeds, contributes to the eutrophication of the lake.

Table 1. The correlations between water quality indices

\begin{tabular}{cccccc}
\hline & $\mathrm{COD}$ & $\mathrm{NH}_{3}-\mathrm{N}$ & $\mathrm{Chl}-\mathrm{a}$ & $\mathrm{TP}$ & $\mathrm{TN}$ \\
\hline $\mathrm{COD}$ & 1 & & & & \\
$\mathrm{NH}_{3}-\mathrm{N}$ & 0.826 & 1 & & & \\
Chl-a & -0.226 & 0.142 & 1 & & \\
$\mathrm{TP}$ & 0.417 & 0.373 & 0.565 & 1 & \\
$\mathrm{TN}$ & 0.988 & 0.838 & -0.114 & 0.497 & 1 \\
\hline
\end{tabular}

Table 1 shows the correlations between water quality indices of Wuxing Lake. It can be seen that chemical oxygen demand (COD), a metric of organic pollutants, is closely correlated with $\mathrm{NH}_{3}-\mathrm{N}$, total nitrogen $(\mathrm{TN})$, and total phosphorus (TP), but weakly correlated with Chl-a. This means COD is basically proportional to the external inputs of 
$\mathrm{NH}_{3}-\mathrm{N}, \mathrm{TN}$, and TP. In addition, $\mathrm{Chl}-\mathrm{a}$ has a strong correlation with $\mathrm{TP}$, and a weak correlation with $\mathrm{TN}$, indicating that $\mathrm{TN}$ has a weaker impact on the eutrophication of the lake than TP. Currently, the pollutants in Wuxing Lake mainly come from non-point source pollution from surrounding farmlands.

\subsubsection{Correlations between nutrients and eutrophication}

In theory, lake eutrophication can be curbed by controlling the contents of nutrients like nitrogen and phosphorus in lake water. In the real world, however, many lakes are polluted to varying degrees. To control lake eutrophication, the first step is to identify the limiting nutrients that induce eutrophication. By regulating the contents of these nutrients, it is possible to mitigate lake eutrophication quickly at a low cost. Therefore, the TN/TP must be investigated thoroughly before handling lake eutrophication.

To date, many scholars have tackled the effect of TN/TP on algal bloom in lakes. In 1983, Smith [9] proposed the law of TN/TP: if the TN/TP is greater than 29, the lake will have few blue-green algae, and a low probability of algal bloom; if the TN/TP is lower than 29 , the algae in the lake will increase substantially, that is, a low TN/TP favors the algae growth. This law was adopted by researchers for a long time. Reynolds $[10,11]$ and Reynolds and Walsby [12] agreed that a low TN/TP is an important cause of algal bloom in lakes. Sakamoto found that algae growth is positively correlated with TN/TP, when TN/TP falls within 10-25. On this basis, Goda Takeshi put the most suitable TN/TP for algae growth in lakes at $12-13$.

Probing deeper into algal bloom in lakes, many researchers began to question the law of TN/TP. For example, Xie et al. [13] and Chen et al. [14] demonstrated that Microcystis growth is related to low TP or TN, but not to the TN/TP, and observed that Microcystis only grows within a certain range of $\mathrm{TN}$ or TP. Wang and Wang [15] argued that it is incorrect to analyze limiting nutrients with TN/TP. Zhang [16] believed that TN/TP is not an antecedent but a consequent of algal bloom.

At present, the TN and TP in Wuxing Lake roughly fall in the corresponding ranges of Class V water: the $\mathrm{TN}$ is greater than $2 \mathrm{mg} / \mathrm{L}$, and above $7 \mathrm{mg} / \mathrm{L}$ at some measuring points; the TP fluctuates between 0.4 and $0.8 \mathrm{mg} / \mathrm{L}$. The TN/TP falls in the range of 4-12. As suggested by some scholars, the correlation between TN/TP and eutrophication can be divided as follows: If TN/TP is smaller than 7, nitrogen is the limiting nutrient of eutrophication; if TN/TP is greater than 7 , phosphorus is the limiting nutrient.

Overall, the TN/TP of Wuxing Lake was between 4 and 12 . From May to June, the Chl-a content was $110 \mathrm{mg} / \mathrm{m}^{3}$, and the TN/TP was 12. In this period, TN and TP decreased at basically the same rate. This means the algae in Wuxing Lake were still growing, and the nitrogen and phosphorus were sufficient to meet the growth demand. At this time, the TN and TP could ensure the algae growth, and neither nitrogen nor phosphorus is limiting nutrient.

In August, the Chl-a content reached the peak of $380 \mathrm{mg} / \mathrm{m}^{3}$. However, the TN/TP remained between 6 and 7 from July to August. Meanwhile, the TN decreased slower than TP.

From August to November, the Chl-a content was decreasing, and the TN/TP stayed below 7. The decline occurred as many algae were removed by fishermen, as a protective measure against the algal bloom in August, and a good portion of algae died in this period. Despite the decline, the Chl-a content remained at a certain level, because the external conditions (e.g. temperature) are suitable for algae growth.

From November to the next March, the Chl-a content exhibited a downward trend, while the TN/TP was smaller than 7. The main reason is the great influence of the external environment during this period, making the algae less dependent on nutrients.

As shown in Figure 2, Chl-a content is weakly correlated with TN/TP. Thus, nitrogen and phosphorus acted as the limiting nutrient of the eutrophication of Wuxing Lake alternatively.

Then, the correlations of TN/TP with TN and TP were fitted, and the results are recorded in Figures 3 and 4 . It can be seen that $\mathrm{Y}_{\mathrm{TP}}=0.0156(\mathrm{TN} / \mathrm{TP})^{3}-0.2651(\mathrm{TN} / \mathrm{TP})+1.5301$, and coefficient of determination was 0.4392 , indicating that TP has a relatively significant effect on TN/TP. Besides, $\mathrm{Y}_{\mathrm{TN}}=00.6193$ (TN/TP)-0.7014, and coefficient of determination was 0.8494 , indicating that the $\mathrm{TN}$ has an extremely significant effect on TN/TP. Hence, TP has a greater impact on the TN/TP than TN. This further confirms that the eutrophication of Wuxing Lake was alternatively controlled by nitrogen and phosphorus.

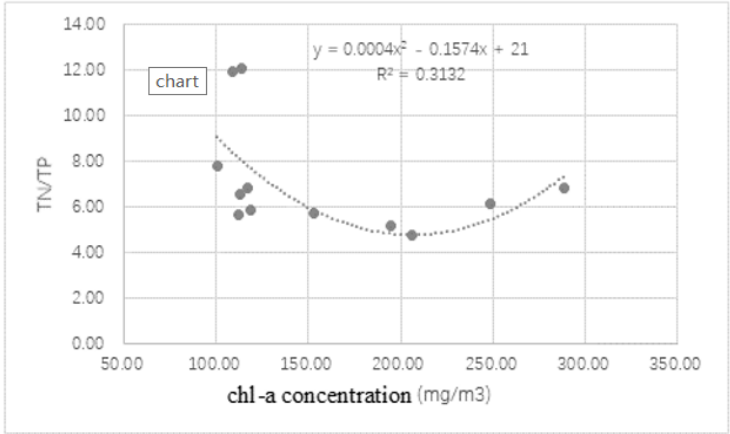

Figure 2. The correlation between TN/TP and Chl-a

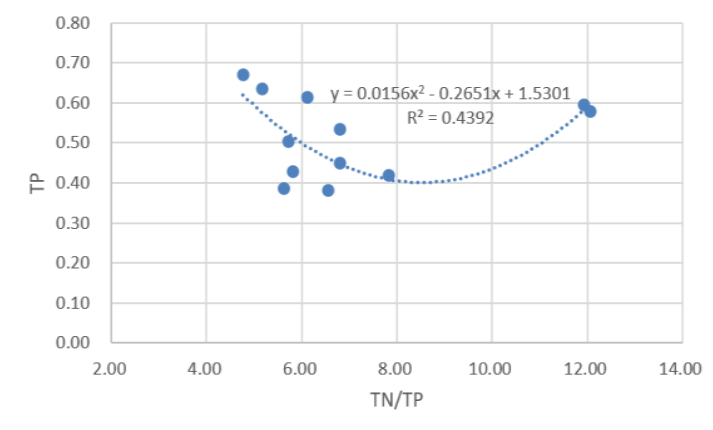

Figure 3. The correlation between TN/TP and TP in Wuxing Lake

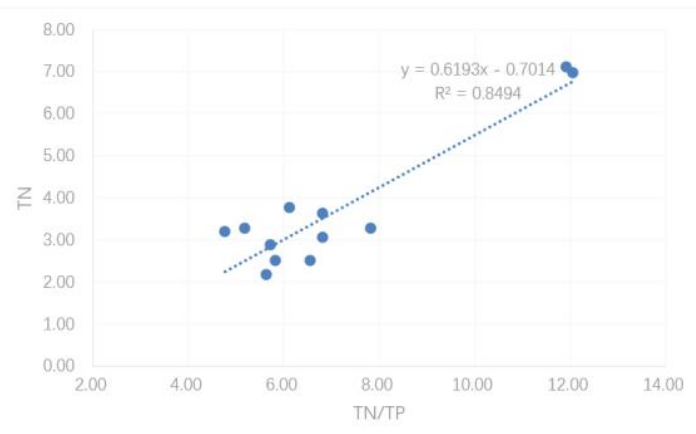

Figure 4. The correlation between $\mathrm{TN} / \mathrm{TP}$ and $\mathrm{TN}$ in Wuxing Lake 


\subsection{Analysis on influencing factors}

Table 2. The normalized data

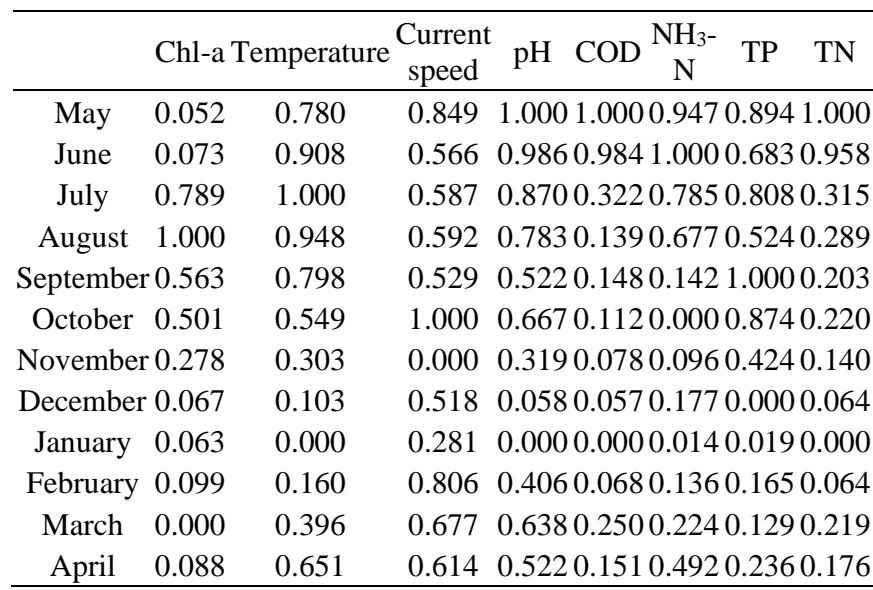

Table 3. The values of $\Delta_{0 \mathrm{i}}(k)$

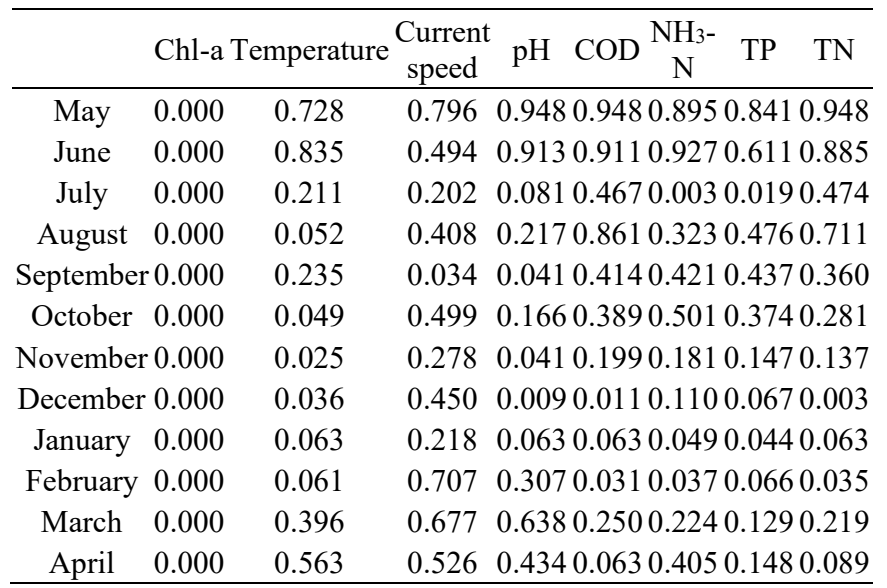

Table 4. The values of $\delta_{0 \mathrm{i}}(k)$

\begin{tabular}{|c|c|c|c|c|c|c|c|}
\hline & $C 111$ & & $\begin{array}{l}\text { Current } \\
\text { speed }\end{array}$ & ${ }^{t} \mathrm{pH}$ & 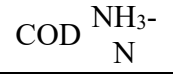 & $\mathrm{TP}$ & $\mathrm{TN}$ \\
\hline May & 1.000 & 0.394 & 0.373 & 0.3 & 3330.34 & 036 & 3 \\
\hline June & & & & & 420 & & 349 \\
\hline July & & & & & 40 & & 0 \\
\hline Aug & & & & 0. & 50. & & .400 \\
\hline & & & & & & & \\
\hline & 1 . & & 0.487 & 0.7 & 490.4 & 0 & 0.628 \\
\hline & 1. & 0 & 0.631 & 0.9 & 040.7 & & .776 \\
\hline Dec & 1.0 & 0.9 & 0.513 & 0.9 & 0.9780 .8 & 0 & 0.993 \\
\hline $\mathrm{J}_{\mathrm{a}}$ & 1.000 & 0.883 & 0.685 & 0.8 & 8830.9060 & 0.915 & 0.883 \\
\hline Febr & 1.000 & & 0.401 & 0.607 & $70.9390 .928 c$ & 0.878 & 0.932 \\
\hline Mar & 1.000 & 0.5 & 0.412 & 0.4 & 60.6550 .6790 & 0.786 & 0.684 \\
\hline April & 1.000 & 0.457 & 0.474 & 0.522 & 20.8820 .5390 & 0.761 & 0.842 \\
\hline
\end{tabular}

Table 5. The degrees of correlation between Chl-a and its influencing factors

\begin{tabular}{|c|c|c|c|c|c|c|}
\hline Index & Temperature & $\begin{array}{c}\text { Current } \\
\text { speed }\end{array}$ & $\mathrm{pH} \quad \mathrm{COD}$ & $\begin{array}{c}\mathrm{NH}_{3}- \\
\mathrm{N}\end{array}$ & $\mathrm{TP}$ & $\mathrm{TN}$ \\
\hline $\begin{array}{l}\text { Degree of } \\
\text { correlation }\end{array}$ & 714 & 0.553 & 0.68 & 30.65 & 0.693 & 0.657 \\
\hline
\end{tabular}

Based on the formation mechanism and influencing factors of eutrophication of Wuxing Lake, which were identified in
Subsection 3.1, this subsection compares the impacts between different influencing factors, providing the basis for the design of proper regulation measures.

Since Chl-a is contained in every phytoplankton, the Chl-a content was adopted to characterize the eutrophication of Wuxing Lake. Therefore, the Chl-a content was taken as the affected factor, while the influencing factors were selected as: temperature, current speed, $\mathrm{pH}, \mathrm{COD}, \mathrm{NH}_{3}-\mathrm{N}, \mathrm{TP}$, and $\mathrm{TN}$.

As mentioned before, Wuxing Lake is a shallow lake with little difference between air temperature and water temperature. Hence, the temperature was defined as the monthly mean temperature of the air. The current speed was determined by averaging the monthly mean values at 9 sampling points in the northern part of the lake. All the other indices were the monthly mean values at the 9 sampling points from May 2015 to April 2016. The original data were normalized by formula (1) (Table 2 ).

The absolute differences $\Delta_{0 \mathrm{i}}(k)$ between every two influencing factors in different months were solved. As shown in Table 3, the maximum and minimum of $\Delta_{0 \mathrm{i}}(k)$ were 0.948 and 0 , respectively, and the $\rho$ value was 0.5 .

Then, the correlation coefficients and degrees of correlation were solved by formulas (2) and (3), respectively. The results are recorded in Tables 4 and 5, respectively.

As shown in Table 5, the influencing factors can be ranked as temperature $>\mathrm{TP}>\mathrm{pH}>\mathrm{TN}>\mathrm{NH}_{3}-\mathrm{N}>\mathrm{COD}>$ current speed in descending order of their degree of correlation with Chl-a content. The greater the degree of correlation, the closer the relationship between the factor with Chl-a content, and the higher its impact on the eutrophication of Wuxing Lake. It is obvious that temperature exerts the greatest effect on lake eutrophication, revealing the important role of external conditions. Nitrogen and phosphorus, as nutrients for algae and other phytoplankton, also contribute greatly to the eutrophication of Wuxing Lake.

\section{CONCLUSIONS}

(1) The severe eutrophication of Wuxing Lake was examined from three perspectives: external conditions, sources of nutrients, and the relationship between nutrients and eutrophication. The results show that the perennial current speed is slower than $0.03 \mathrm{~m} / \mathrm{s}$; the temperature from April to October is between $10^{\circ} \mathrm{C}$ and $30^{\circ} \mathrm{C}$, and the mean sunshine duration is $2,375 \mathrm{~h}$. These conditions are suitable for algae growth, creating favorable external conditions for eutrophication. Besides, the correlation analysis between nutrient sources and water quality indices demonstrates that agricultural non-point source pollution is the main source of nutrients and pollutants in the lake. In addition, nitrogen and phosphorus alternatively act as the limiting nutrient in Wuxing Lake. TN/TP cannot characterize the lake eutrophication, unless the TN and TP exceed standards. Finally, low TN/TP is the result of algal bloom.

(2) The degrees of correlation of Chl-a with temperature, current speed, $\mathrm{pH}, \mathrm{COD}, \mathrm{NH}_{3}-\mathrm{N}, \mathrm{TP}$, and $\mathrm{TN}$ were analyzed, based on sample data collected from the northern part of Wuxing Lake. Through the analysis, the influencing factors were ranked as temperature $>\mathrm{TP}>\mathrm{pH}>\mathrm{TN}>\mathrm{NH}_{3}-$ $\mathrm{N}>\mathrm{COD}>$ current speed in descending order of their degree of correlation with Chl-a content. Among them, temperature exerts the greatest effect on lake eutrophication, revealing the important role of external conditions. Nitrogen and 
phosphorus, as nutrients for algae and other phytoplankton, also contribute greatly to the eutrophication of Wuxing Lake.

\section{ACKNOWLEDGMENT}

This research is supported by Key Scientific Research Projects 2019, North Minzu University (Grant No.: 2019KJ24); Ningxia Natural Science Foundation (Grant No.: 2019AAC03134; 2018AAC03115); High Level Talent Introduction Fund Project, North Minzu University; Ningxia Key Research and Development Plan (Talent Introduction) (Grant No.: 2018BEB04039).

\section{REFERENCES}

[1] Wang, D.Y., Feng, X.Z., Zhou, L.G., Hao, J.Y., Xu, X.X. (2008). Relationship between blue algal bloom and water temperature in Lake Taihu based on MODIS. Journal of Lake $\quad$ Sciences, $20(2)$ : 173-178. https://doi.org/10.18307/2008.0206

[2] Li, Y., Zhang, L.F., Huang, C.P., Wang, J.N., Cen, Y. (2016). Monitor of cyanobacteria bloom in Lake Taihu from 2001 to 2013 based on MODIS temporal spectral data. Spectroscopy and Spectral Analysis, 36(5): 14061411. https://doi.org/10.3964/j.issn.1000-0593(2016)051406-06

[3] Jorge-García, D., Estruch-Guitart, V. (2020). Economic valuation of ecosystem services by using the analytic hierarchy process and the analytic network process. comparative analysis between both methods in the Albufera Natural Park of València (Spain). International Journal of Design \& Nature and Ecodynamics, 15(1): 14. https://doi.org/10.18280/ijdne.150101

[4] Teta, R., Della Sala, G., Mangoni, A., Lega, M., Costantino, V. (2016). Tracing cyanobacterial blooms to assess the impact of wastewaters discharges on coastal areas and lakes. International Journal of Sustainable Development and Planning, 11(5): 804-811. https://doi.org/10.2495/SDP-V11-N5-804-811

[5] Teta, R., Esposito, G., Casazza, M., Zappa, C.J., Endreny, T.A., Mangoni, A., Costantino, V., Lega, M. (2019). Bioindicators as a tool in environmental impact assessment: Cyanobacteria as a sentinel of pollution. International Journal of Sustainable Development and Planning, 14(1): 1-8. https://doi.org/10.2495/SDP-V14N1-1-8
[6] Gao, F., Feng, M.Q., Han, S.X., Bai, J.Z. (2016). Numerical simulation research on flow characteristics and influential factors of Wuxing Lake. International Journal of Heat and Technology, 34(1): 80-88. https://doi.org/10.18280/ijht.340112

[7] He, F., Wang, J., Chen, X.J. (2020). Comprehensive ecological management of black and smelly open channels: Evidence from Wuhan, China. International Journal of Design \& Nature and Ecodynamics, 15(3): 299-307. https://doi.org/10.18280/ijdne.150303

[8] Anazoba, C.J., Eneji, I.S., Sha'Ato, R. (2019). Water quality and heavy metals contamination of artificial lakes in Heipang and Rayfield, Plateau State, Nigeria. Environmental and Earth Sciences Research Journal, 6(3): 112-118. https://doi.org/10.18280/eesrj.060303

[9] Smith, V.H. (1983). Low nitrogen to phosphorus ratios favor dominance by blue-green algae in lake phytoplankton. $\quad$ Science, $221(4611)$ : 669. https://doi.org/10.1126/science.221.4611.669

[10] Reynolds, C.S. (1972). Growth, gas vacuolation and buoyancy in a natural population of a planktonic bluegreen alga. Freshwater Biology, 2(2): 87-106. https://doi.org/10.1111/j.1365-2427.1972.tb00364.x

[11] Reynolds, C.S. (1973). Growth and buoyancy of Microcystis aeruginosa KUTZ. emend. Elenkin in a shallow eutrophic lake. Proceedings of the Royal Society of London, 184(1074): 29-50. https://doi.org/10.1098/rspb.1973.0029

[12] Reynolds, C.S., Walsby, A.E. (1975). Water blooms. Biological Reviews, 50(4): 437-481. https://doi.org/10.1111/j.1469-185X.1975.tb01060.x

[13] Xie, L.Q., Xie, P., Li, S., Tang, H.J., Liu, H. (2003). The low TN:TP ratio, a cause or a result of Microcystis blooms. Water Research, 37(9): 2073-2080. https://doi.org/10.1016/S0043-1354(02)00532-8

[14] Chen, G.Y., Yang, Z.B., Ma, Y., Tao, M.X. (2007). Effects of nitrogen and phosphorus on growth of Microcystis aeruginosa strains. Journal of Environment and Health, 9: 675-679. https://doi.org/10.1007/s11767005-0212-9

[15] Wang, H.J., Wang, H.T. (2009). Eutrophication control should relax nitrogen control and concentrate phosphorus control. Progress in Natural Science, 19(6): 599-604. https://doi.org/10.3321/j.issn:1002-008X.2009.06.003

[16] Zhang, Y. (2014). Development Three-Dimensional Hydrodynamic Water Quality Model Shallow Eutrophic Reservoir. Tian Jin: Tianjin University. https://doi.org/10.7666/d.D655245 